\title{
Spinal cord hemorrhage in a patient with neurosarcoidosis on long-term corticosteroid therapy: case report
}

\author{
Benoit Pegat ${ }^{*}$, Sophie Drapier ${ }^{1}$, Xavier Morandi ${ }^{2}$ and Gilles Edan ${ }^{1}$
}

\begin{abstract}
Background: Central nervous system bleeding is a rare complication of neurosarcoidosis: only 18 cases of spontaneous cerebral hematoma have been reported. We present the first recorded case of spinal cord hemorrhage in neurosarcoidosis.

Case presentation: A 48-year-old Caucasian woman had relapsing neurosarcoidosis for 5 years, with inflammatory spinal and cerebral lesions. While on $20 \mathrm{mg}$ corticosteroids, she experienced subacute paraparesia with right leg pain. A spine MRI revealed a low thoracic hematomyelia at the T10-T11 level. Despite high doses of corticosteroids, her condition continued to worsen. Surgical evacuation of the hematoma was performed 10 days after the onset of bleeding, and she partially recovered.

Conclusion: This report highlights the possibility of spinal cord hemorrhage secondary to sarcoid vasculitis. The patient improved after surgical evacuation of the intramedullary hematoma. Immuno-modulating agents must be envisaged in severe neurosarcoidosis, to prevent complications.
\end{abstract}

Keywords: Hematomyelia, Hemorrhage, Spinal cord, Neurosarcoidosis, Magnetic resonance imaging, Corticosteroid

\section{Background}

Sarcoidosis is a multisystemic granulomatosis characterized by non-caseating granulomas [1]. In $5-7 \%$ cases, it may involve the neurological system [2-4]. Spinal cord sarcoidosis occurs in about $6 \%$ of all neurosarcoidosis cases $[3,5,6]$. Although several pathological studies have reported microvascular changes in neurosarcoidosis $[7,8]$, bleeding is rare. Only 18 cases of cerebral hemorrhage have been reported [9-12], and four of these concerned patients on corticosteroid therapy [10, 13-15]. We present the first recorded case of spinal cord hemorrhage in a 48-year-old Caucasian woman who had been treated with corticosteroids for 5 years for relapsing neurosarcoidosis.

\section{Case presentation}

Sarcoidosis was histologically proven at 30 years, with pulmonary biopsy revealing non caseating granulomas

\footnotetext{
*Correspondence: benoit.pegat@gmail.com

'Department of Neurology, Pontchaillou Hospital, Rennes University Hospital, Rennes, France

Full list of author information is available at the end of the article
}

when the patient presented with erythema nodosum and bilateral hilar adenopathy. Onset of neurosarcoidosis occurred 13 years later, characterized by cauda equina syndrome with a sensorimotor deficit in the right leg. Magnetic resonance imaging (MRI) revealed diffuse enlargement of the spinal cord, with high T2-weighted signal intensity from T8 to the L1-L2 level (Fig. 1a). There was no enhancement on gadolinium-enhanced T1-weighted images of the spine. Cerebral MRI was normal. Cerebrospinal fluid (CSF) tests revealed aseptic lymphocytic meningitis, with 540 cells $/ \mathrm{mm}^{3}$ and a protein concentration of $375 \mathrm{mg} / \mathrm{dL}$. Oligoclonal bands were absent, and the blood level of angiotensinconverting enzyme was normal. The patient's condition improved after high doses of intravenous steroids, followed by oral corticosteroids (starting at $1 \mathrm{mg} / \mathrm{kg}$ / day, then tapering). CSF returned to normal after 4 months' treatment. The leg dysesthesia persisted, as did bladder disturbances, treated by intermittent selfcatheterization.

Two years later, the patient had a relapse, while on steroids $(4 \mathrm{mg} /$ day), characterized by gait ataxia and 

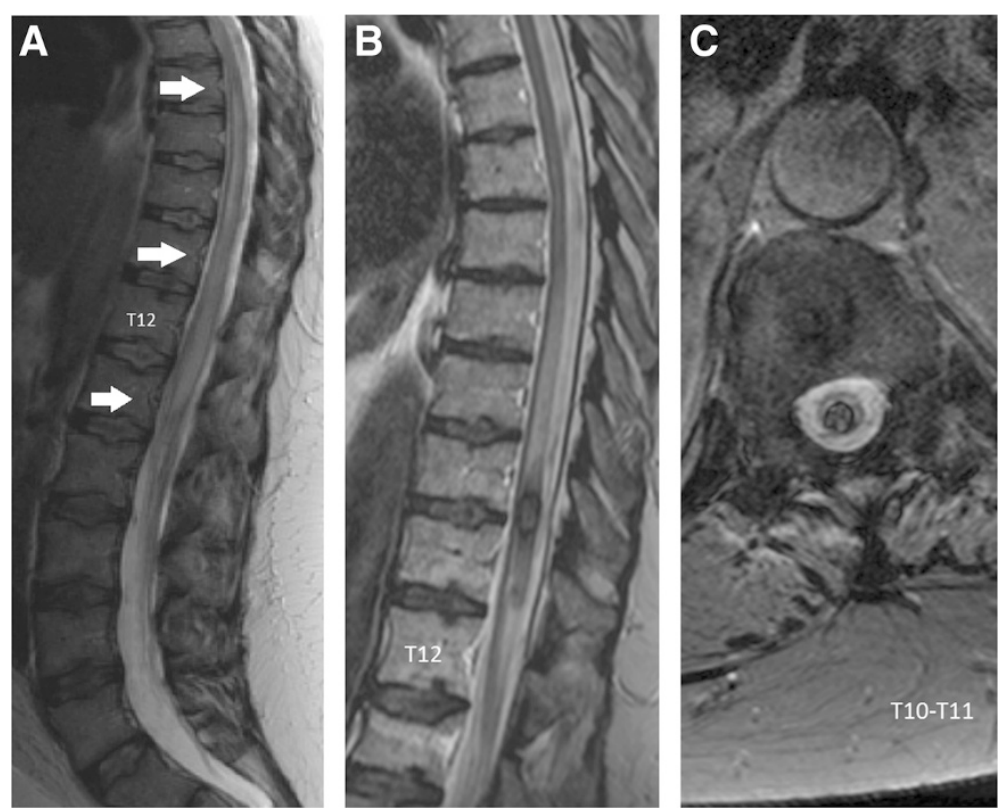

Fig. 1 Spinal MRI images of the first inflammatory event (a) and the hematomyelia (b and $\mathbf{c}$ ). a. Sagittal T2-weighted MRI showing a high-intensity signal and enlargement of the spinal cord extending from T8 to the L1-L2 level. b. Sagittal T2-weighted turbo spin-echo MRI showing a heterogeneous low-intensity signal at the T10-T11 level. c. Transversal T2*-weighted gradient-echo MRI at the T10-T11 level confirming the intramedullary low-intensity signal: it is an intramedullary hemorrhage (hematomyelia)

cognitive impairment, inflammatory activity in the CSF (40 cells $/ \mathrm{mm}^{3}$, protein concentration of $137 \mathrm{mg} / \mathrm{dL}$ ) and multifocal lesions on a brain MRI (Fig. 2a-b). T2fluid attenuation inversion recovery (FLAIR) and T2*weighted gradient-echo imaging showed a low-intensity frontoparietal lesion identified as blood deposits. Steroids were increased to $1 \mathrm{mg} / \mathrm{kg} /$ day and she showed a marked improvement. Follow-up CSF analysis indicated fewer than 10 cells $/ \mathrm{mm}^{3}$, and oligoclonal bands were found this time.

Three years later, while on corticosteroids $(20 \mathrm{mg} /$ day), the patient experienced paroxysmal right leg pain, acute worsening of gait difficulties (unable to walk alone owing to a major motor deficit in the right leg) and urinary retention. Sensory examination revealed a sensitive level at L3, with lower-limb hypoesthesia, and decreased pelvic sensation. Spinal MRI revealed a large heterogeneous intramedullary lesion at T10-T11, with a low-intensity $\mathrm{T} 2{ }^{*}$-weighted gradient-echo signal, diagnosed as hematomyelia (Fig. 1b-c). Part of the medullary cone was enhanced by gadolinium in a T1-weighted sequence. Coagulation blood tests and platelets were normal. Despite high doses of intravenous corticosteroids, she became paraplegic within 10 days, with a sensory deficit
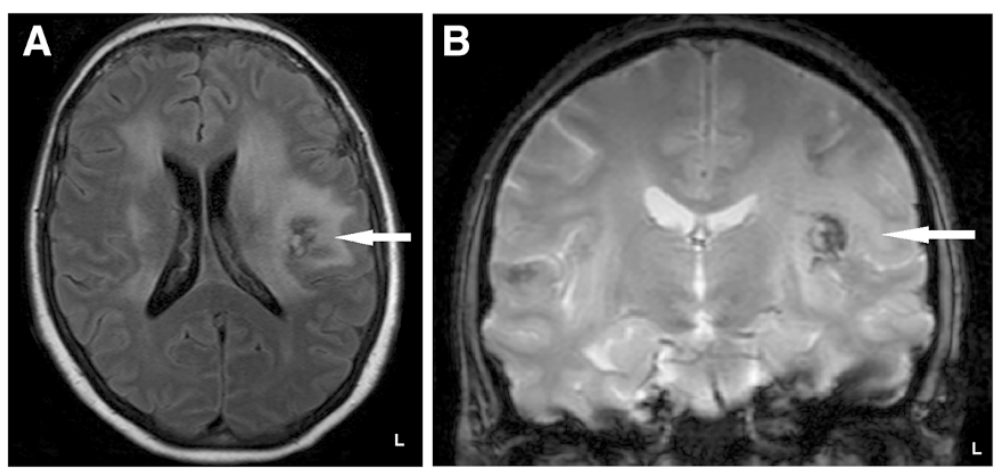

Fig. 2 Cranial MRI images of the second inflammatory episode. a. Axial T2 fluid attenuation inversion recovery (FLAIR)-weighted MRI indicating large, high-intensity periventricular lesions, and a low-intensity left frontoparietal lesion. $\mathbf{b}$. Coronal T2*-weighted gradient-echo MRI confirming the presence of a low-intensity lesion, suggestive of hemosiderin deposits, that had not been found on previous MRIs 
at the T12 level. A neurosurgical intervention was performed to evacuate the hematoma, without any additional complications. The neurosurgeon observed numerous abnormally enlarged blood vessels on the back of the spinal cord. Histological analysis of spinal cord tissue did not reveal any abnormal cells.

After yearlong intensive rehabilitation, the patient remained paraparetic, with a severe deficit in the right leg ( $3 / 5$ on motor scale), but was nonetheless able to walk with a walking frame. Adding an immune-modulating agent was discussed but not done, because of a severe infectious complication of a pressure ulcer that required 6 weeks' hospitalization in intensive care. Four years after the hematomyelia, the patient was on a daily dose of just $4 \mathrm{mg}$ corticosteroids and remained relapse free, with no new lesions on follow-up MRI.

\section{Discussion}

In the case described here, the diagnosis of neurosarcoidosis was definite according to Judson's criteria [16] and probable according to Zajicek's [17]. This first report highlights the possibility of spinal cord hemorrhage in patients with neurosarcoidosis, as suggested by Waubant and colleagues, who described hemosiderin deposits in spinal-cord sarcoidosis [18].

Common causes of atraumatic hematomyelia $[19,20]$ include vascular malformations (arteriovenous fistula, cavernoma, capillary telangiectasia, venous angioma) [21], neoplasms, Gowers'intrasyringal hemorrhage, spinal radiation, anticoagulation and bleeding disorders. None of these applied to our patient, suggesting that her hematomyelia was caused by bleeding of a spinal cord granuloma, given the proximity of the first inflammatory lesion (T8-L1) to the hemorrhage (T10-T11).

Despite the lack of histological confirmation of the source of bleeding, there is sufficient evidence from cerebral cases [9] to suggest that hemorrhage in neurosarcoidosis may be caused by vascular pathologies (venous, arteriolar, or micro-arterio-venous malformations) induced by the disease itself. Sarcoid granulomas in the central nervous system (CNS) follow perivascular spaces and penetrate brain parenchyma [22]. Post mortem examinations of intracranial hemorrhage in neurosarcoidosis have revealed perivascular inflammatory infiltrate and vessel wall destruction by granulomas $[7,9]$. The enlarged blood vessels noticed by the neurosurgeon in our patient seem to support the hypothesis of neurosarcoid vasculitis. The frontoparietal hemorrhage that occurred during the second episode, 3 years before the hematomyelia (Fig. 2a-b), is also suggestive of the fragility of blood vessels in the CNS damaged by the neurosarcoid vasculitis.

Long-term corticosteroids also increase vascular fragility, owing to reduced collagen formation in vessel walls [23], but there was no evidence to suggest that steroids directly caused the bleeding here. Indeed, we decided to increase the corticosteroid dose, as adding an immunomodulating agent to control the neurosarcoid vasculitis (and spare corticosteroids) was not possible because of an infectious complication. There have not been any randomized controlled trials of pharmacological treatments for neurosarcoidosis, but the algorithm developed by Nozaki and Judson, has proved useful for severe neurosarcoidosis [24].

Kreppel and colleagues' meta-analysis [25] is the largest review of reports of spinal hematoma published before 1996. These authors reviewed 613 patients belonging to four etiological groups of spinal cord hemorrhage: intramedullary (hematomyelia), subarachnoidal, subdural and epidural. Hematomyelia was found in only $0.82 \%$ of patients, possibly owing to the dearth of MRI-based diagnosis prior to 1996. More recently, Leep and colleagues [19] and Heldner and colleagues [20] reviewed the diagnosis, cause and treatment of hematomyelia. Hematomyelia can present as an acute, subacute, step-wise or chronic myelopathy [19]. As it did in our case, neurological deterioration can occur after the initial hemorrhage, owing to a secondary tissue response [19]. It is essential to monitor vital signs and neurological status in the intensive care unit, to prevent complications [20]. However, there have not been any clinical trials comparing different ways of managing hematomyelia $[19,20]$, notably the timing of hematoma evacuation. In our case, the decision to operate was made because of a progressive, rapid and inexorable neurological deterioration. There was a definite, but not total, clinical improvement following treatment for this rare and severe complication of neurosarcoidosis.

\section{Conclusion}

This report presents the first case of intramedullary spinal cord hemorrhage complicating neurosarcoidosis, which improved following surgical evacuation. Neurosarcoid vasculitis may have favored this rare complication. Immuno-modulating agents could be envisaged as a means of preventing the complications of longterm corticosteroid therapy and vasculitis in severe CNS neurosarcoidosis.

\section{Consent}

Written informed consent was obtained from the patient for publication of this Case report and any accompanying images. A copy of the written consent is available for review by the Editor of this journal.

\section{Abbreviations}

CNS: Central nervous system; CSF: Cerebrospinal fluid; MRI: Magnetic resonance imaging; FLAIR: Fluid attenuation inversion recovery.

Competing interests

The authors declare that they have no competing interests. 


\section{Authors' contributions}

All the authors interviewed and examined the patient. XM operated on the patient. The draft was written by BP, but SD, XM and GE contributed references and undertook a critical review. All authors read and approved the final manuscript.

\section{Acknowledgements}

We are grateful to Drs Hélène Raoult and Jean-Christophe Ferré for their assistance in collecting and interpreting the MRI data.

\section{Author details}

'Department of Neurology, Pontchaillou Hospital, Rennes University Hospital, Rennes, France. ${ }^{2}$ Department of Neurosurgery, Pontchaillou Hospital, Rennes University Hospital, Rennes, France.

Received: 17 November 2014 Accepted: 6 July 2015

Published online: 30 July 2015

\section{References}

1. lannuzzi MC, Rybicki BA, Teirstein AS. Sarcoidosis. N Engl J Med. 2007;357:2153-65.

2. Stern BJ, Krumholz A, Johns C, Scott P, Nissim J. Sarcoidosis and its neurological manifestations. Arch Neurol. 1985;42:909-17.

3. Gascon-Bayarri J, Mana J, Martinez-Yelamos S, Murillo O, Rene R, Rubio F. Neurosarcoidosis: report of 30 cases and a literature survey. Eur J Intern Med. 2011:22:e125-32.

4. Morimoto T, Azuma A, Abe S, Usuki J, Kudoh S, Sugisaki K, et al. Epidemiology of sarcoidosis in Japan. Eur Respir J. 2008;31:372-9.

5. Duhon BS, Shah L, Schmidt MH. Isolated intramedullary neurosarcoidosis of the thoracic spine: case report and review of the literature. Eur Spine J. 2012;21 Suppl 4:S390-5.

6. Junger SS, Stern BJ, Levine SR, Sipos E, Marti-Masso JF. Intramedullary spinal sarcoidosis: clinical and magnetic resonance imaging characteristics. Neurology. 1993;43:333-7.

7. Libman RB, Sharfstein S, Harrington W, Lerner P. Recurrent intracerebral hemorrhage from sarcoid angiitis. J Stroke Cerebrovasc Dis. 1997;6:373-5.

8. Caplan L, Corbett J, Goodwin J, Thomas C, Shenker D, Schatz N. Neuroophthalmologic signs in the angiitic form of neurosarcoidosis. Neurology. 1983;33:1130-5

9. O'Dwyer JP, Al-Moyeed BA, Farrell MA, Pidgeon CN, Collins DR, Fahy A, et al. Neurosarcoidosis-related intracranial haemorrhage: three new cases and a systematic review of the literature. Eur J Neurol. 2013;20:71-8.

10. Spencer TS, Campellone JV, Maldonado I, Huang N, Usmani Q, Reginato AJ. Clinical and magnetic resonance imaging manifestations of neurosarcoidosis. Semin Arthritis Rheum. 2005;34:649-61.

11. Tsappidi S, Hui F, Turan TN, Hunter S. Intracerebral hemorrhage: an unusual presentation of neurosarcoidosis. Neurologist. 2011;17:292-6.

12. Lettau M, Laible M, Treier M. Infarction with subarachnoid hemorrhage from vasculitis with neurosarcoidosis. Rofo. 2011;183:573-5.

13. Dakdouki GK, Kanafani ZA, Ishak G, Hourani M, Kanj SS. Intracerebral bleeding in a patient with neurosarcoidosis while on corticosteroid therapy. South Med J. 2005;98:492-4.

14. Eid H, O'Connor $\mathrm{CR}$, Catalano E, Reginato AJ. Life-threatening vasculitis associated with sarcoidosis. J Clin Rheumatol. 1998;4:338-43.

15. Lavrnic DV, Vidakovic AB, Apostoloski S, Stefanova ED, Stevic-Marinkovic Z Intracerebral hemorrhage in a female patient with pulmonary sarcoidosis. Srp Arh Celok Lek. 1992:120:363-6.

16. Judson MA, Baughman RP, Teirstein AS, Terrin ML, Yeager Jr H. Defining organ involvement in sarcoidosis: the ACCESS proposed instrument. ACCESS Research Group. A Case Control Etiologic Study of Sarcoidosis. Sarcoidosis Vasc Diffuse Lung Dis. 1999:16:75-86.

17. Zajicek JP, Scolding NJ, Foster O, Rovaris M, Evanson J, Moseley IF, et al. Central nervous system sarcoidosis-diagnosis and management. QJM. 1999:92:103-17.

18. Waubant E, Manelfe C, Bonafe A, Berry I, Clanet M. MRI of intramedullary sarcoidosis: follow-up of a case. Neuroradiology. 1997;39:357-60.

19. Leep Hunderfund AN, Wijdicks EF. Intramedullary spinal cord hemorrhage (hematomyelia). Rev Neurol Dis. 2009:6:E54-61.

20. Heldner MR, Arnold M, Nedeltchev K, Gralla J, Beck J, Fischer U. Vascular diseases of the spinal cord: a review. Curr Treat Options Neurol. 2012;14:509-20.
21. Anson JA, Spetzler RF. Interventional neuroradiology for spinal pathology. Clin Neurosurg. 1992;39:388.

22. Herring $A B$, Urich $H$. Sarcoidosis of the central nervous system. J Neurol Sci. 1969;9:405-22.

23. Hein R, Mauch C, Hatamochi A, Krieg T. Influence of corticosteroids on chemotactic response and collagen metabolism of human skin fibroblasts. Biochem Pharmacol. 1988;37:2723-9.

24. Nozaki K, Judson MA. Neurosarcoidosis: clinical manifestations, diagnosis and treatment. Presse Médicale. 2012;41:e331-48.

25. Kreppel D, Antoniadis G, Seeling W. Spinal hematoma: a literature survey with meta-analysis of 613 patients. Neurosurg Rev. 2003;26:1-49.

\section{Submit your next manuscript to BioMed Central and take full advantage of:}

- Convenient online submission

- Thorough peer review

- No space constraints or color figure charges

- Immediate publication on acceptance

- Inclusion in PubMed, CAS, Scopus and Google Scholar

- Research which is freely available for redistribution 